\title{
Ecotourism and impact of the COVID-19 pandemic on ecotourism in Tan Cuong tea area of Vietnam
}

\author{
Thi Ngoc Ha Tran, Thu Huong Nguyen \\ Thai Nguyen University of Science, Vietnam \\ DOI: 10.29322/IJSRP.11.08.2021.p11625 \\ http://dx.doi.org/10.29322/IJSRP.11.08.2021.p11625
}

\begin{abstract}
The article focuses on studying the current status of ecotourism development and the impact of the COVID-19 pandemic on ecotourism in Tan Cuong tea area of Vietnam. By using the SWOT model and methods of data collection, analysis, processing, field observation, survey of 200 tourists and 222 tea growing households, the research showed real results.

In recent years, ecotourism activities of the Tan Cuong tea area have attracted many domestic and foreign tourists to visit and experience. Ecotourism products are improved with a variety of services.

However, the arrival of the COVID-19 pandemic in early 2020 had a huge impact on local tourism. The number of tourists to Tan Cuong tea area in 2020 was only $25 \%$ of the total number of tourists in the same period last year. Along with that, 198/222 interviewed households (accounting for $89,2 \%$ ) said their income was affected by the decrease in tourist arrivals.

From the results obtained, the study offers some solutions to solve people's livelihood problems during the complicated development of the COVID-19 pandemic and prepare resources to develop tourism when the pandemic is repelled.
\end{abstract}

Index Terms- Ecotourism, tourists, COVID 19, Tan Cuong, Vietnam

\section{INTRODUCTION}

$\mathrm{T}$ he COVID-19 pandemic had a strong impact on the whole world, causing unprecedented negative impacts on the economies of the world and Vietnam. The outbreak of COVID-19 that started in China and then spread around the world at a rapid pace (A.B. Nashirah et al.,2020) [1]. The European Center for Disease Control and Prevention (ECDC) has warned that the Covid-19 epidemic is infecting and claiming many lives (H.T.Nguyen et al.,2020) [2]. According to statistics of the COVID-19 acute respiratory infection website (Vietnam Ministry of Health) on June 10, 2021, the total number of infected people worldwide reached over 175 million. In which, the number of deaths is nearly 3.8 million people (accounting for $2.17 \%$ of infected people). In Vietnam, the total number of infections was 9,636 people and 55 deaths (accounting for $0.57 \%$ ) at the same time. Thus, the Covid 19 pandemic in Vietnam and around the world has been very stressful. It had a great impact on human life and health, socio-economic, especially the tourism industry. (T.H.Pham et al.,2020; A.B.Nashirah et al.,2020; H.T.Nguyen et al.,2020) [1,2,3].

Before the arrival of the COVID-19 pandemic, tourism was a large industry worldwide with an average annual growth rate of $4-5 \%$, contributing $8 \%$ of global GDP and $10 \%$ of employment (Gurel Cetin, 2020) [4]. Many studies show that tourism is also the industry most vulnerable to crises from: natural disasters, epidemics ... and the COVID-19 pandemic is an undeniable proof. The COVID 19 crisis is estimated to have 7 times more impact on tourism than the 2008 financial crisis, a $39 \%$ decrease in tourist arrivals [4].

In Vietnam, the tourism industry is oriented as a key industry in economic development. The diversity of ecosystems, nature and the uniqueness of local culture have promoted tourism to become an important economic sector of Vietnam (accounting for nearly $10 \%$ of the country's GDP) (H.T.Nguyen et al., 2018) [2]. But the complicated developments of the COVID-19 epidemic have caused heavy damage to Vietnam's tourism industry. According to the statistics of March 2020, the number of international visitors to Vietnam is 449.9 thousand, down $68.1 \%$ over the same period in 2019. In which, visitors coming by plane decreased by $65.7 \%$, by road by $77.9 \%$ and by sea by $55.2 \%$ (Gurel Cetin, 2020) [4]. Thereby, the profits of airlines, travel companies and the income of workers in the tourism industry decreased sharply.

Tan Cuong tea area is located in the northeast of Vietnam. It belongs to Thai Nguyen province. This is a semi-mountainous land, beautiful natural landscape with green tea hills. For a long time, the specialty of Tan Cuong tea has been famous throughout the country and known by many people. These are favorable factors to develop ecotourism of this famous tea area. As of June 10, 2021, Thai Nguyen province has only recorded 10 cases of infection (of which only 1 is being treated, all other cases have recovered) and Tan Cuong has no cases of infection. However, ecotourism in Tan Cuong tea area has also been facing many difficulties due to the disease outbreak in the world and other localities. This study aims to understand the impacts of the COVID-19 pandemic on people's livelihoods and ecotourism activities in Tan Cuong tea area. Thereby offering solutions to limit the losses caused by the COVID-19 pandemic to local tourism activities 


\section{METHODOLOGY}

Collect, analyze and process data: The data (natural conditions, socio-economic conditions, tourism activities of the locality ...) are collected from departments, branches of Thai Nguyen province and People's Committee of Tan Cuong Commune. Collected data were analyzed and processed for use in the article.

Fieldwork, survey: Surveyed 222 typical tea growing households of 4 hamlets: Hong Thai 1, Hong Thai 2, Soi Vang, Go Phao to study the effects of COVID-19 on tourism, people's life and income.

The number of households was selected according to Slovin's formula (1) (T.K.T. Tran, 2012) [5]:

$$
n=\frac{N}{1+N(e)^{2}}
$$

Note: n: Number of household to be surveyed (222 households)

$\mathrm{N}$ : Number of households growing tea in 4 hamlets (500 households)

e: Allowed error. Choose e $=5 \%$ (95\% confidence level).

The number of surveyed households in each research hamlet was randomly selected based on the total number of households in each hamlet with the ratio of surveyed households: [(212/449)x100] $=44.4 \%$.

Table 1:- Number of surveyed households in Tan Cuong tea area

\begin{tabular}{lcc}
\hline Hamlets & Tea growing household & Survey household \\
\hline Hong Thai 1 & 150 & 67 \\
\hline Hong Thai 2 & 170 & 75 \\
\hline Go Phao & 100 & 44 \\
\hline Soi vang & 80 & 36 \\
\hline Total & $\mathbf{5 0 0}$ & $\mathbf{2 2 2}$ \\
\hline
\end{tabular}

In addition, the study investigated 200 tourists coming to Tan Cuong to analyze the potentials and difficulties of local tourism.

\section{RESULT AND DISCUSSION}

\subsection{Evaluation of ecotourism development in Tan Cuong tea area}

Using the SWOT model to evaluate ecotourism development in Tan Cuong tea area, specifically:

Strength and opportunities for ecotourism development in Tan Cuong commune (S - O)

The popularity of Tan Cuong tea: Tan Cuong was formed in the mid-20s of last century (T.Q.Duong, 2011) [6]. Tan Cuong tea tree was brought to this area by Mr. Doi Nam (real name Vo Van Thiet) in 1922. He was also the one who set up planting areas, production workshops and opened tea shops. Currently, Tan Cuong tea brand is not only famous in the country but also exported to many countries around the world such as France, India, China...

Tan Cuong tea area has 16 hamlets. All the hamlets have tea growing and processing activities. The number of tea-growing and processing households was nearly 1500 (accounting for 80\%) (People's Committee of Tan Cuong Commune, 2020) [7]. Typically, 4 hamlets with a high percentage of tea growing and processing households were Hong Thai 1 (78.9\%), Hong Thai 2 (100\%), Go Phao (93.45\%), Soi Vang (77.6\%) (Table 2).

Table 2:- Percentage of tea growing and processing household in Tan Cuong tea area

\begin{tabular}{rlccc}
\hline TT & Hamlets & Households & Total & Percentage (\%) \\
\hline 1 & Hong Thai 1 & 150 & 190 & 78,9 \\
2 & Hong Thai 2 & 170 & 170 & 100 \\
3 & Go Phao & 100 & 107 & 93,45 \\
4 & Soi Vang & 80 & 103 & 77,6 \\
\hline & Total & $\mathbf{5 0 0}$ & $\mathbf{5 7 0}$ & $\mathbf{8 7 , 7}$ \\
\hline
\end{tabular}

*Source: Survey results in 2020

The effective radiation in Tan Cuong was $61.2 \mathrm{Kcal} / \mathrm{cm}^{2} /$ year (lower in other regions was $122.4 \mathrm{Kcal} / \mathrm{cm}^{2} / \mathrm{year}$ ), the temperature difference between days and the night was about $7.9^{\circ} \mathrm{C}$ (higher than other areas), so it was very suitable for the growth and development conditions of tea plants (Thai Nguyen International Tea Festival - Viet Nam 2011) [8]. Many tea products were created to meet the needs of customers such as: jasmine-marinated tea, lotus-marinated tea...

Thus, the first potential for ecotourism development in Tan Cuong commune was the popularity and diversity of tea products. 
Geographical location: Tan Cuong commune is located in the West of Thai Nguyen city. Convenient transportation is one of the advantages for local tourism development. Around Tan Cuong tea area, there are many entertainment places that attract tourists such as: Nui Coc Lake, Thai Hai ecological stilt village, Wonderland film studio...

\section{Weaknesses and threats in ecotourism development in Tan Cuong commune (W-T)}

The survey results of 200 tourists showed that $85 \%$ of tourists only stopped to take pictures, the remaining $15 \%$ (30 people) of tourists participated in experience services. Among them, $70 \%$ (21 people) of tourists said that the service provided was suitable for their cost, $30 \%$ ( 9 people) tourists were satisfied with the service (eating, resting). However, there were $60 \%$ (18 people) showed that tourism services need to be more diverse to keep tourists staying longer. Tan Cuong has 2 establishments with accommodation activities in Tan Cuong: Mr. Bui Trong Dai's household (Tien Yen tea brand) and Mr. Nguyen Van Thang's household (both in Hong Thai 2). According to them, the number of overnight guests was very small, each year only accounting for about 3-5\% of the total number of tourists. From 2020 onwards, tourists used this service much less due to the COVID-19 pandemic.

Thus, local ecotourism activities have abundant potential but have not really developed. The income of people from ecotourism was not high, mainly concentrated in a few households, other households still rely mainly on selling tea and tea products.

\subsection{Impact of the COVID-19 pandemic on ecotourism in Tan Cuong tea area}

Number of tourists: The figure for tourists to Tan Cuong continuously increased from 2010-2019 (the strongest increase in the years of organizing the Thai Nguyen International Tea Festival). But from 2020 until now, the number of tourists tends to decrease, especially the number of international tourists (table 3, figure 1).

Table 3:- Number of tourists to Tan Cuong tea area (2010-2020)

\begin{tabular}{ccc}
\hline Year & Tourists (passengers) & Note \\
\hline 2010 & 6.000 & The 1st Thai Nguyen Tea International Festival \\
2011 & 8.000 & \\
2012 & 10.000 & The 2nd Thai Nguyen Tea International Festival \\
2013 & 12.000 & \\
2014 & 12.500 & The 3rd Thai Nguyen Tea International Festival \\
2015 & 14.000 & \\
2016 & 15.000 & \\
2017 & 16.000 & \\
2018 & 17.800 & \\
2019 & 20.000 & \\
2020 & 5.000 & The 4th Thai Nguyen International Tea Festival \\
& & (scheduled to take place in April 2020) is postponed due to the COVID-19 epidemic
\end{tabular}

*Source: Tan Cuong tea Administration

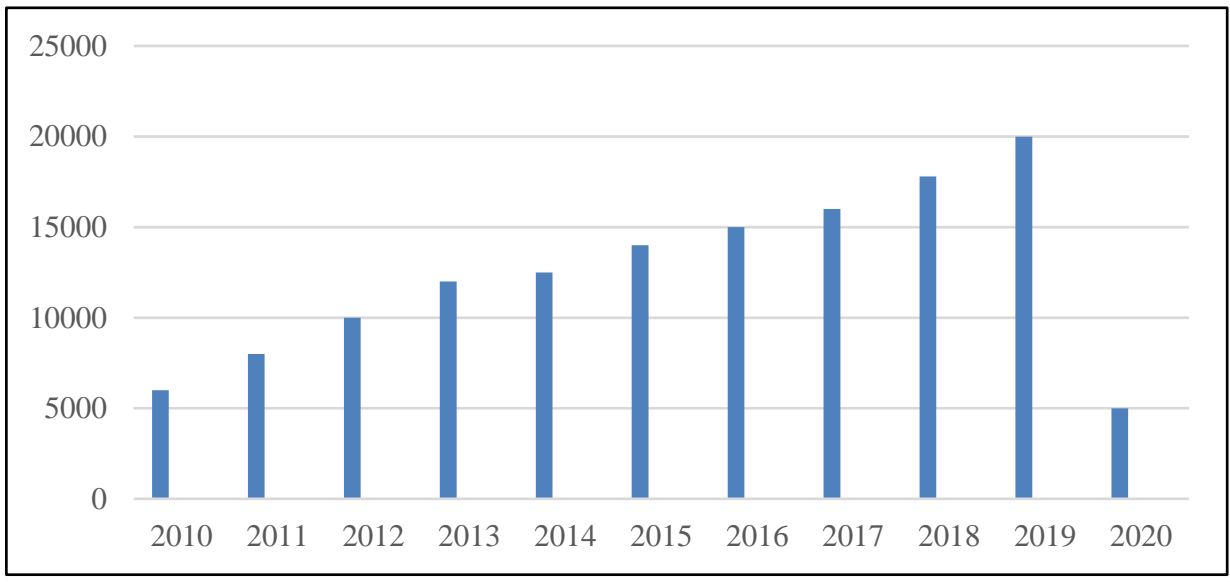

Figure 1:- Number of tourists to Tan Cuong tea area (2010-2020)

The figure showed the highest number of tourists to Tan Cuong in 2019. This was the year that Tan Cuong prepared resources for the organization of the 4th Thai Nguyen International Tea Festival (in 2020).

In the years of organizing the Thai Nguyen International Tea Festival, the number of tourists coming to Thai Nguyen were very large. For example, in 2013, the 2nd Tea Culture Festival attracted 73 domestic and 6 international delegations (Japan, India, Sri Lanka, 
Korea, China) to attend. According to statistics in 2019, the number of foreign tourists coming to Tan Cuong tea area accounted for about $16 \%$ of the total number of tourists (People's Committee of Tan Cuong Commune). Although the number of international delegations was not too much, they fully experienced tourism services when coming to the locality. Revenue from international tourists was quite high.

Unfortunately, the plan to organize the 4th Thai Nguyen Tea International Festival scheduled from April 17 to 19, 2020 (Plan No. 06/KH-UBND dated January 6, 2020 of Thai Nguyen Provincial People's Committee) must be stopped (due to the COVID-19 pandemic). In 2020, the number of tourists to Tan Cuong area was only 1/4 of the number of tourists in 2019. This was a big loss for Tan Cuong tourism.

\section{Income of people}

Tourism income includes all revenues from accommodation, meals, transportation, sales of souvenirs, etc. Total tourism revenue of Thai Nguyen city increased rapidly (from 185 billion VND in 2015 to 430 billion VND in 2019) (Department of Culture, Sports and Tourism, Thai Nguyen Province). But by 2020, due to the impact of the COVID-19 pandemic, travel services, entertainment activities, entertainment ... have been severely affected. When the first outbreak took place (strongly between January-April 2020 ), over $90 \%$ of guests canceled their booked tours. In 2020, the number of tourists to Thai Nguyen only reached 1.16 million, down $63 \%$ compared to 2019 (table 4). Travel companies had to cut staff. Some businesses were temporarily closed and employees were laid off. About $80 \%$ of the tourism workforce was unemployed for many months (Department of Culture, Sports and Tourism, Thai Nguyen Province). In 2020, total tourism revenue of Thai Nguyen province dropped sharply (table 4, figure 2).

Table 4:- Total tourism revenue of Thai Nguyen province (2015-2020)

\begin{tabular}{ccc}
\hline Year & $\begin{array}{c}\text { Tourists } \\
\text { (passengers) }\end{array}$ & $\begin{array}{c}\text { Total tourism revenue } \\
\text { (billion VND) }\end{array}$ \\
\hline 2015 & 1.930 .000 & 185 \\
2016 & 2.060 .000 & 205 \\
2017 & 2.229 .700 & 310 \\
2018 & 2.530 .000 & 405 \\
2019 & 2.925 .000 & 430 \\
2020 & 1.160 .000 & 150 \\
\hline
\end{tabular}

* Source: Department of Culture, Sports and Tourism of Thai Nguyen Province

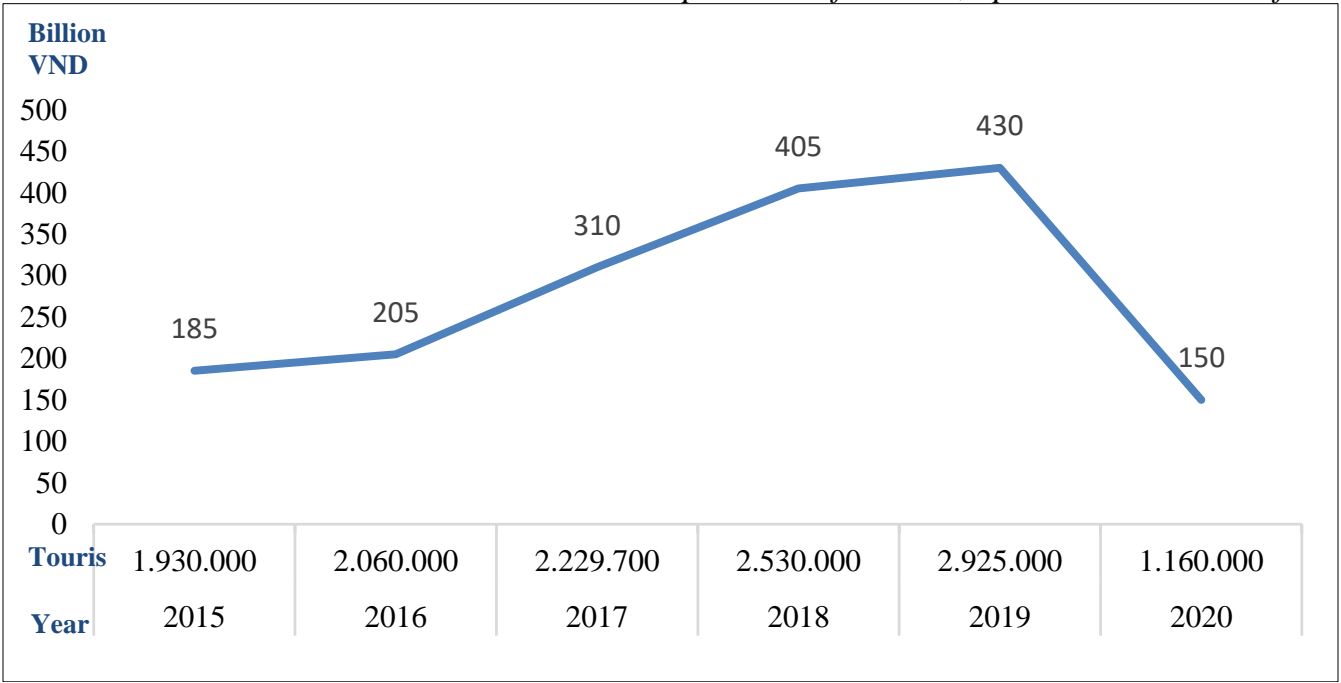

Figure 2:- Total tourism revenue of Thai Nguyen province (2015-2020)

Figure 2 showed that the number of tourists was directly proportional to the total tourism revenue. In 2020, Thai Nguyen's total tourism revenue was the lowest due to the lowest number of tourists coming to Thai Nguyen.

Research results showed that 198/222 households (89.2\%) were affected by the decrease in tourist arrivals due to the COVID19 pandemic (table 5, figure 3).

Table 5:- Households with income affected by the COVID-19 in Tan cuong area

\begin{tabular}{lcc}
\hline $\begin{array}{l}\text { Level of influece } \\
\text { (People's opinion) }\end{array}$ & Number of households with income affected \\
\cline { 2 - 3 } & Amount & Percentage $(\%)$ \\
\hline
\end{tabular}




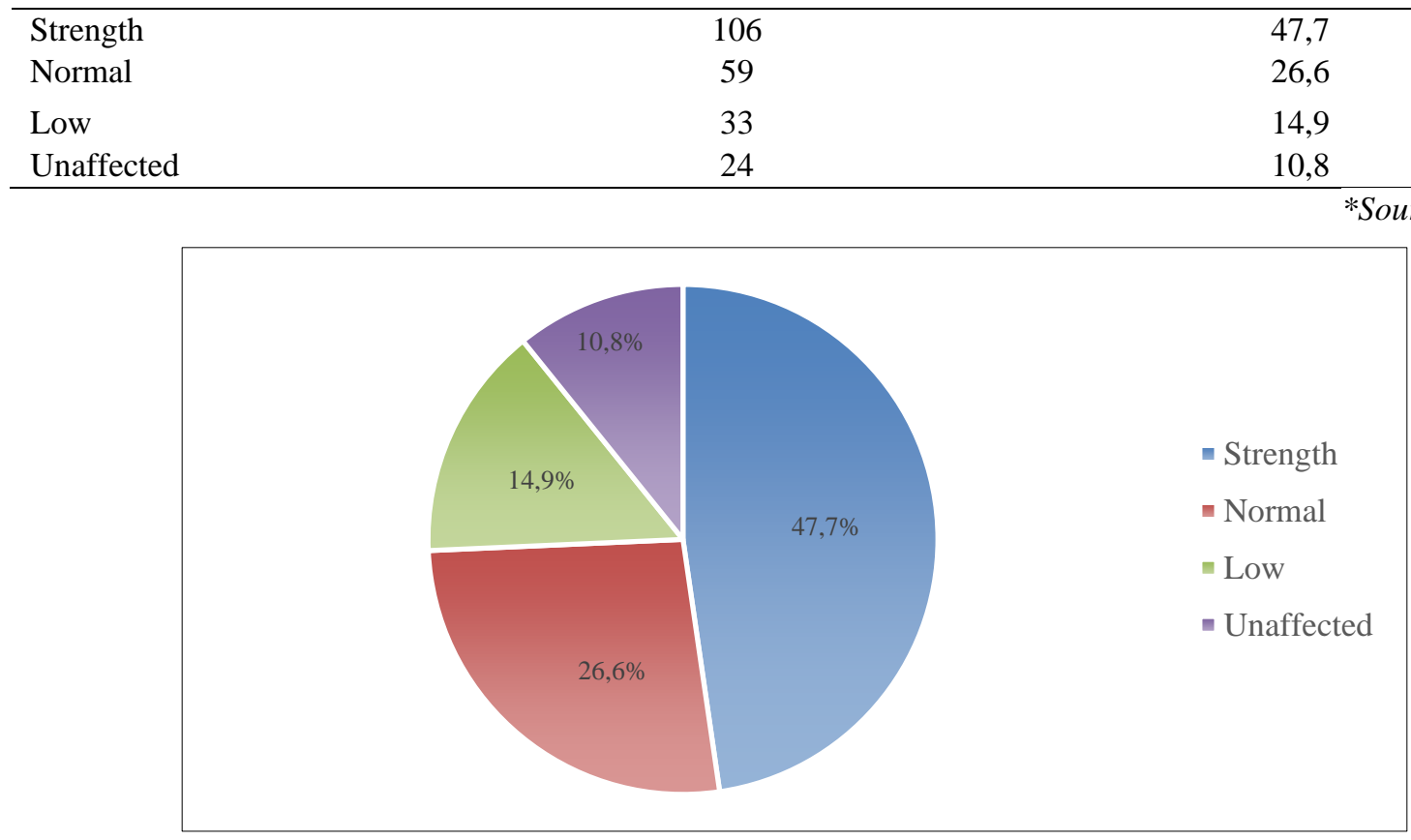

Figure 3:- Percentage of households with income affected by the COVID-19 in Tan Cuong tea area

As shown in figure 2, the number of households strongly affected by the decrease in tourist arrivals accounts for the highest proportion $(44,7 \%)$. The number of unaffected household accounts for the lowest percentage $(10,8 \%)$.

In general, the COVID-19 pandemic has greatly affected the ecotourism and livelihoods of people in Tan Cuong tea area.

\subsection{Discussion}

The COVID-19 pandemic has been affecting many countries around the world, including Vietnam. Although no one has been infected, the pandemic has seriously affected the life, economy and society of Tan Cuong. Research has proven that the number of tourists to Tan Cuong decreased sharply from 2020 onwards. This had a strong impact on people's income. Therefore, the study offers a number of solutions for tourism to build better forward.

Firstly, advertise tourism products through electronic information sites, social networks, and mass media. Thereby, products (tea, peanut candy, green tea powder...) will be delivered to consumers, solving the livelihood problems of the people. The form of advertising needs to be diverse (short clips, photos, skits, experiential activities, contests, games...) and the content should be rich (history, local beauty, cultural features...).

Secondly, good implementation of pandemic prevention measures will create peace of mind for tourists when coming to the locality. If tourism activities are resumed, measures to prevent epidemics such as: organizing tours for small groups of tourists, not joining groups (to avoid contact between groups of strangers), regularly cleaning and disinfecting the area.

Finally, promote vaccination and propagate the role of vaccination to all people and visitors.

\section{CONCLUSION}

The results showed that Tan Cuong tea area had great potential for developing ecotourism. The number of tourists to Tan Cuong continuously increased from 2010-2019. Ecotourism products were increasingly rich and attractive, attracting domestic and foreign tourists.

The COVID-19 pandemic has had a great impact on the life, economic and income of people in Tan Cuong. The number of tourists decreased, the revenue from tourism activities also decreased significantly.

\section{REFERENCES}

1. A.B. Nashirah, Sofian Rosbi, "Effect of Coronavirus disease (COVID-19) to tourism industry", International Journal of Advanced Engineering Research and Science (IJAERS), pp 189-193, 4/2020.

2. H. T. Nguyen, V. S. Tran (2020), Sustainable development of tourism industry in the post-Covid 19 period in Vietnam - Marketing Approach, Thu Dau Mot University, 7/2020.

3. T. H. Pham, H. D. Tran, Đ. A. Ngo, "Impact of the COVID-19 pandemic on Vietnam's tourism industry and solutions", (in Vietnamese), The Journal of Economic and Development, No 274, pp 156-164, 2020.

4. Gurel Cetin, "Impact of Covid-19 on Tourism Industry", Journal of Tourismology, Istanbul university press 4/2020.

5. T. K. T. Tran, Sociological investigation method, (in Vietnammese), National Economics University Publishing house (NEUPH), Ha Noi, 2012.

6. T. Q. Duong, "Vietnamese tea and Thai Nguyen tea", (in Vietnammese), Thai Nguyen tea International Conference 2011, pp 11-16, 2011. 


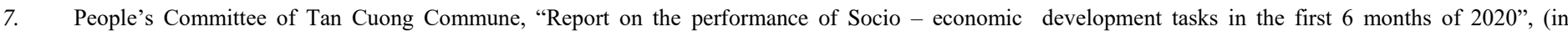
Vietnammese), Thai nguyen, 2020.

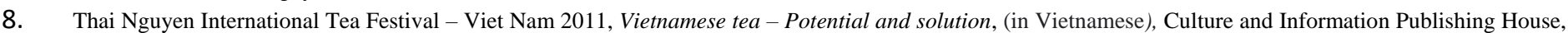
2012.

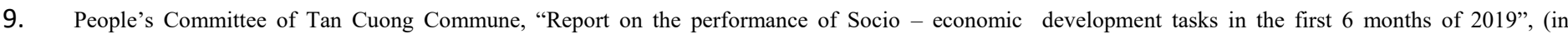
Vietnammese), Thai nguyen, 2019.

\section{AUTHORS}

First Author - Thi Ngoc Ha Tran, Thai Nguyen University of Science, Vietnam

Second Author - Thu Huong Nguyen, Thai Nguyen University of Science, Vietnam

Correspondence Author - Thi Ngoc Ha Tran, Thai Nguyen University of Science, Vietnam hattn@tnus.edu.vn 